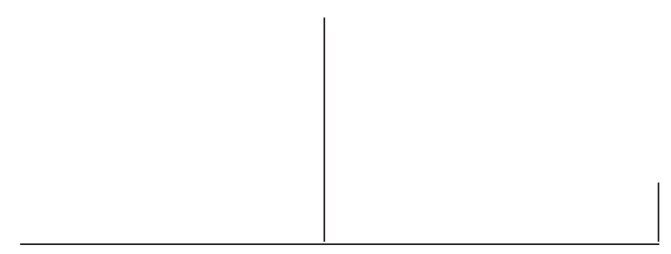

Rev. Latinoam. Psicopat. Fund., IV, 4, 43-60

\title{
Análise com borda e análise sem borda*
}

\author{
François Duparc
}

Quais são os limites da representação, além dos quais o sujeito se vê confrontado ao irrepresentável?

As representações comportam diferentes níveis de maturidade; conseqüentemente o irrepresentável comporta graus, é relativo. Isso explica a esperança que se conserva no tratamento dos estados-limite, ou de certas formas de psicoses, de perversões ou de distúrbios psicossomáticos.

Cada nível de representação comporta seu tipo de limite, sua bordadura, seu negativo, graças ao qual ele pode entrar em contato e se ligar tanto com o nível que o precede quanto com aquele que lhe sucede e o contém. Trata-se de um modelo da ordem da auto-organização, com níveis de complexidade crescente.

O limite pode ser tanto interno, constituindo, então, um limite elaborado, psiquizado, integrado no pára-excitações, quanto externo, apelando a um enquadre, a um apoio externo do qual o sujeito fica, então, extremamente dependente para seu equilíbrio narcísico, e mesmo vital.

Os pacientes- "limite" são justamente sujeitos dependentes de um enquadre auto-erótico externo, enquadre com freqüência

* Tradução de Monica Seincman 


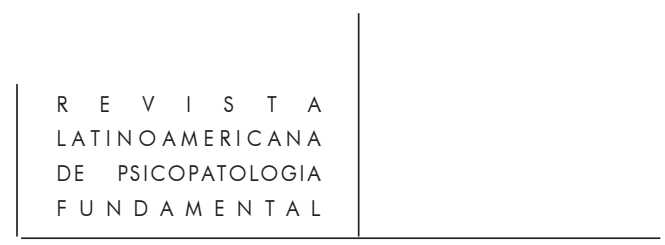

faltante, pois muito flexível, pouco adaptado às aleatoriedades da realidade, como o sugere a imagem da carapaça. Suas pulsões, malcontroladas por representações primárias, em que a figuração perceptiva domina a ligação verbal, têm tendência a se descarregarem brutalmente a partir do momento em que o objeto externo, ou aquilo que o substitui, falta em sua função de apoio.

O "trabalho nos limites" do analista é feito com uma avaliação da parte irrepresentável de que o paciente sofre, e de uma técnica adaptada de auxílio à representação, adaptada a cada estrutura e a cada história. Isso será ilustrado com casos clínicos.

Palavras-chave: Representações, limites, negativo, enquadre, apoio

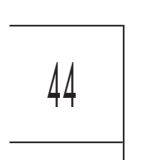

\section{Abertura}

"Eu me pergunto o que constitui o limite, quando a gente cuida de crianças", diz-me esta enfermeira em análise há algum tempo. "Principalmente, os bebês em dificuldade. A gente sente neles uma tal necessidade de serem segurados, embrulhados, olhados, acalentados com palavras. A gente pode se apaixonar por uma criança, sabia? Assim como por um animal, ou como se tem um homem na pele. Não venha me dizer que é sexual, não tem nada a ver... Eu encontrei um educador, é verdade, que me disse que nunca poderia cuidar de crianças anormais, pois ele não sabia se poderia evitar ter relações com elas. Quando era adolescente, ele transou com animais. É preciso que se diga que ele foi praticamente educado por seu cachorro: é um caso à parte. Mas eu me pergunto, mesmo assim, como pode se constituir o limite. Não venha me dizer que é a moral. Isso é muito abstrato, não se sustenta na prática, quando se sente esta proximidade com uma criança."

Esta paciente, que pensava ser uma ciclotímica, em virtude de acessos depressivos agudos, ${ }^{1}$ teve por muito tempo dificuldade em acreditar que ela podia ter

1. Tendo a pensar que este diagnóstico está correto à medida que ela apresentava também episódios de hiperatividade e relativa euforia, alternando com a volta periódica de idéias suicidas agudas, mas, para mim, isso não significa que uma causa biológica esteja automaticamente em questão, nem sobretudo, mesmo neste caso, que um determinismo psicossomático esteja ausente, muito pelo contrário. Cf. Duparc 1989, 1998. 


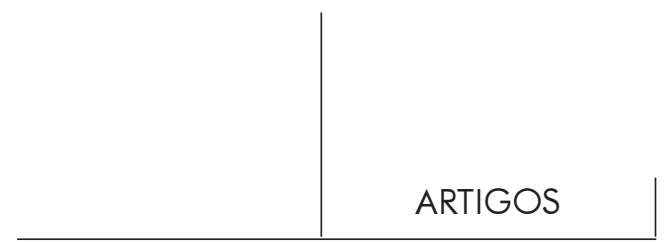

influência sobre suas perturbações por meio da análise. Na sessão anterior, seguindo o fio de suas associações, e no interior de uma interpretação que recaía sobre seu desejo de ser olhada, fiz-lhe involuntariamente um elogio. Apesar de minha formulação bastante indireta, ela logo reparou e ficou extremamente tocada, comovida às lágrimas. No início de seu tratamento, tal perturbação na neutralidade do enquadre tê-la-ia logo levado a uma recaída grave, com ameaça de interrupção do tratamento - tanto em um sentido como no outro: eu ter negligenciado observar um movimento de sedução ou de aproximação, ou, pelo contrário, ter-lhe feito alusão.

Desta vez, ela me traz um sonho, mas não tem recaída. Não contarei todo o seu sonho, o que me obrigaria a precisões excessivas, mas somente que ele terminava com esta imagem: ela estava em uma praia quando, de repente, uma onda enorme apareceu no mar, aumentando gradativamente. Ela tinha muito medo, mas conseguiu contrapor uma barreira. Este sonho representava para ela um grande progresso na figuração de uma emoção sexual que a superava (neste caso certamente aquela provocada pela minha interpretação), como os cuidados de sua mãe em sua primeira infância, ou os gestos incestuosos de seu pai na adolescência dela.

Nesta paciente, a imagem de um núcleo autístico (no sentido que lhe dá $\mathrm{F}$. Tustin [1989]) sempre me pareceu uma metáfora interessante para explicar seus ciclos melancólicos; núcleo de noite, núcleo mais irrepresentado do que irrepresentável. Suas afirmações iniciais, relativas às crianças, seguiam, aliás, justamente esta linha. Mas, graças à análise, a constituição de um obstáculo representativo, ilustrado pelo sonho, havia permitido uma atenuação considerável dos acessos tímicos que se traduziam até então em ondas alternadas de excitação e depressão.

Parecia-me justo dizer, como ela o fazia em uma fórmula de aspecto genérico, que para ela o limite moral funcionava mal, apesar de uma hiperescrupulosidade calcada sobre a de sua mãe. E sua questão mais de uma vez retornou: qual limite, já que o domínio superegóico ainda não funciona? Qual barreira encontrar para as ondas de um funcionamento psíquico submetido a uma pulsão que visa a descarga muito pouco ou malrepresentada?

Os analisantes de hoje, casos difíceis ou estados-limite, não datam de ontem, contrariamente ao que freqüentemente se escuta. ${ }^{2}$ Mas é necessário esperar que se especifiquem e se clareiem certos conceitos - clivagem, enquadre, identificação projetiva, contratransferência - para que a análise lhe possa ser útil. A noção de

2. Creio escutar por vezes "No meu tempo, havia estações verdadeiras" de certos analistas que falam com nostalgia das neuroses "clássicas" que se supõe terem existido no tempo de Freud. Com efeito, sabe-se bem que as "cinco psicanálises" relatadas por Freud eram tudo menos clássicas isso já foi observado. 


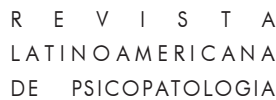

representação faz parte destas noções-chave e isto é normalmente admitido a partir do momento em que nos interessemos pelo irrepresentável como um limite do analisável.

Esta noção de irrepresentável é, ela mesma, uma noção-limite, uma noção discutível. E, no entanto, ela nos guia muito nas indicações que estabelecemos para um tratamento analítico, para privilegiar este ou aquele parâmetro técnico, este tipo de intervenção ou de interpretação, até mesmo para preferir uma psicoterapia face a face, um relaxamento ou um psicodrama. É ao preço deste apoio na representação que, às vezes, pode-se colocar em movimento uma psicanálise, processo de representação por excelência, em casos que pareceriam anteriormente contraindicados.

O irrepresentável é relativo ou absoluto? Será que se trata de um "ainda não representável" pelo próprio sujeito ou de uma aporia definitiva, uma nova rocha do biológico? Temos aí uma pergunta que Freud se fez a propósito do Isso, parte inacessível do inconsciente. Mas o analista de hoje, assim como o cientista, não renuncia com tanta facilidade a tornar representável o que é a priori inacessível. Por que renunciaria ele, já que todos os buracos negros foram confirmados pelos astrônomos, e que a rocha do biológico está a ponto de se tornar cada vez mais transparente para os biólogos, no momento mesmo em que começamos a transitar com a extrema intimidade do desconforto em um percurso a céu aberto, para estabelecer sua cartografia?

Faz agora algum tempo que eu me interesso pela seguinte idéia: o irrepresentável, o negativo, depositam-se preferivelmente sobre as paredes do processo analítico, sobre seu enquadre (Duparc, 1989 e 1998b). Trabalhar para tornar este enquadre invisível, irrepresentável, para que ele mesmo se torne objeto de representação, parece-me, então, constituir a questão do trabalho nos limites da psicanálise. Isso equivale, na prática, a colocar que o apoio psicoterapêutico de um tratamento deve ser abandonado cedo ou tarde, e ser o objeto de uma análise à medida que o analista sinta-se capaz disso. Isso leva igualmente a dissolver a noção de psicoterapia analítica no interior de um processo analítico com enquadre variável, o que não impede o analista de manter uma certa idéia de seu funcionamento ideal.

Aliás, não existe, a meu ver, demanda de análise sem carência de representação, sem irrepresentável relativo, sobre um ponto ou outro - caso contrário, o sujeito se viraria bem sozinho, ou com seu meio habitual, para fazer sua auto-análise. Pareceme cada vez mais que mesmo o enquadre analítico de um tratamento clássico ${ }^{3}$

3. Três ou quatro sessões por semana, em posição deitada sobre o divã, assumidas pelo próprio paciente, este sendo capaz de associar livremente e suportar interpretações limitadas a uma evidenciação na transferência de mecanismos de deslocamento e condensação. 


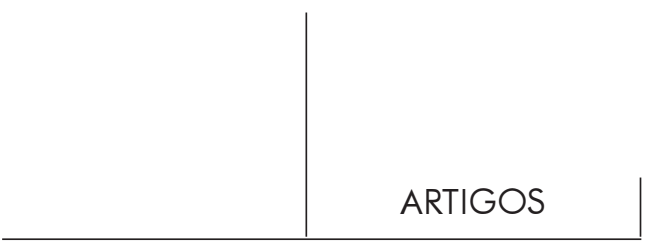

constitui, inicialmente, um apoio psicoterapêutico, um enquadre pára-excitante irrepresentável para o paciente, fonte de análises intermináveis.

Face à vertigem que estas interrogações suscitam, convém retornar um pouco à prática. Quando nos encontramos em face de um paciente que parece difícil, um tipo de avaliação, mais ou menos consciente, põe-se em marcha na escuta do analista. O que chamávamos antigamente de uma avaliação diagnóstica não se contenta mais, hoje em dia, em apreciar uma sintomatologia, e mesmo uma estrutura psicopatológica, guiando-se por mecanismos defensivos - evitações fóbicas, racionalizações obsessivas, projeções narcísicas etc. -, mesmo com o apoio de uma atenção extrema aos esboços transferenciais-contratransferenciais. Um novo critério se desenha: o que, para este paciente, constitui seu núcleo de irrepresentável e de obstáculo em que se origina para ele a compulsão à repetição de um auto-erotismo faltante, a estrutura caracterial que assume o papel de um envelope pára-excitante dispendioso, ineficaz? Enfim, qual modo de apoio ele espera para ajudá-lo a desempenhar, em sua cena psíquica, a representação de sua história não-elaborada e não-assumível, escondida sob uma couraça caracterial e auto-erótica congelada, para aceder ao encontro do novo, este critério essencial da boa saúde psíquica?

\section{Limites da representação}

Em um trabalho anterior (1989b e 1998b), já me esforcei para mostrar que as representações comportam diferentes níveis de maturidade; conseqüentemente, o irrepresentável conhece graus, é relativo. Daí a esperança de que se conserva no tratamento dos estados-limite, ou de certas formas de psicoses, perversões ou distúrbios psicossomáticos.

Cada nível de representação comporta seu tipo de limite, sua bordadura, seu negativo, graças ao qual pode entrar em contato e se ligar tanto com o nível que o precede quanto com aquele que o sucede e o contém. Não se trata de um engate como com as "bonecas russas", mas sim de um modelo da ordem da autoorganização, com níveis de complexidade crescente. ${ }^{4}$

Este limite pode ser tanto interno, constituindo então uma barreira elaborada, psiquizada, integrada no pára-excitações; quanto externo, apelando a um enquadre, a um apoio externo do qual o sujeito está, então, extremamente dependente para seu equilíbrio narcísico, e mesmo vital.

Os pacientes-"limite" são precisamente sujeitos dependentes de um enquadre auto-erótico externo, enquadre freqüentemente ausente, pois muito vago, pouco adaptado às eventualidades da realidade, como o sugere a imagem da carapaça. Suas

4. Cf. o trabalho de Sylvie e Georges Pragier, "Psychanalyse et sciences: nouvelles métaphores". 


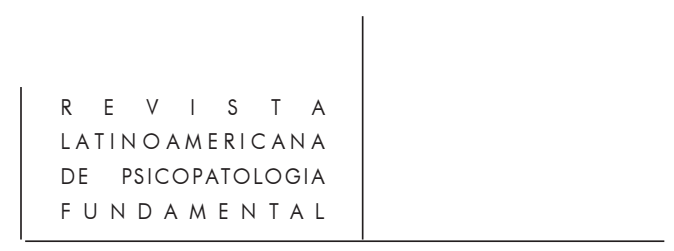

pulsões, malcontroladas por representações primárias, em que a figuração perceptiva domina a ligação verbal, tendem a se descarregar brutalmente desde que o objeto exterior, ou aquilo que ocupa seu lugar, falhe em sua função de apoio. Eles vêm naturalmente se fixar sobre os limites do enquadre fornecido pelo analista.

Mas existem outros limites. Os do tratamento, por exemplo, que separam o paciente do sujeito liberado da tutela da análise, capaz de um certo grau de auto-análise; limites que os candidatos à análise interminável não conseguem superar.

Qual a natureza desses limites, nos diferentes níveis de representação?

a) No nível verbal, o mais elaborado, é um limite natural, o do silêncio. Entretanto, para constituir um limite eficaz, é ainda necessário que este silêncio não seja nem imposto por uma inibição ansiosa, nem excessivo, nem invasivo; que ele seja o que eu chamei de uma simples "respiração da fala" (Duparc, 1988 e 1998b). Esta respiração permite abrir a representação verbal, torná-la acolhedora ao desconhecido vindo de si ou do outro, à diferença e aos jogos de sombra do desejo. Por sua abertura, ela integra em si mesma sua castração simbólica, que a impede, para sempre, de se constituir em certeza hermética a qualquer novidade, a qualquer desejo vivo. Ela lhe permite também articular-se com as representações anteriores, em um diálogo com as representações primárias do inconsciente, preencher-se em momentos fecundos de regressão. Em contrapartida, uma fala "operatória" é uma língua presa que sufoca qualquer diálogo com as camadas primárias da psique, assim como com a verdade inapreensível do outro. É uma linguagem feita de equações simbólicas, que transforma as palavras em coisas, e visa a ocultar todas as zonas de sombra da linguagem.

Assim, esta jovem mulher veio para a análise com o objetivo de melhor se compreender e, se possível, eliminar suas contradições. Adolescente, sonhou tornarse filósofa, superar as paixões; ela se imaginava um velho sábio de barba branca. Na análise, fala profusamente; seu discurso tinha um objetivo de controle, que felizmente pouco a pouco the escapava. Tomada nas contradições de sua fala, ela afundava na confusão e se encolerizava contra si mesma. Quando se tornou capaz de fazer uma ligação com seu medo em relação à sua feminilidade, ao interior invisível de seu corpo e de seu inconsciente, conheceu períodos de silêncio em que a emoção a invadia; inicialmente, emoções com conteúdos sexuais, depois, impressões de mergulhar comigo nas profundezas de uma gruta submarina. Ela sentia tornar-se novamente um bebê no ventre da mãe. Mas isso não acontecia sem angústia. Onde ela ia assim, e onde ia me levar junto? Ela tinha a impressão de fazer como este espeleólogo que desceu em uma gruta para nela passar semanas, sem contato com o mundo externo. Mas dali saiu um tanto enlouquecido.

5. Alusão ao "pensamento operatório" dos psicossomatistas da Escola de Paris; cf. F. Duparc, "L’opératoire, entre clivage et forclusion", 1998a. 




Sua angústia de castração assumia, então, um duplo aspecto: por um lado, o medo de me levar consigo em um abismo em que eu arriscava a minha potência (angústia de castração do objeto), por outro, o medo de perder sua própria capacidade de representação ao ser confrontada com o invisível. No entanto, sua fala enriquecia-se com uma profundidade associativa incomparável em relação ao início de seu tratamento, abrindo na representação verbal o que gosto de designar como sua "boca de sombra".

b) No nível da figuração imaginária, a representação é, certamente, mais dependente de uma colocação em imagem que procura reproduzir a percepção. $\mathrm{O}$ trabalho do pré-consciente a infiltra, apesar de toda a sua potência associativa e suas conexões com as figuras de estilo próprias à linguagem. Estamos aqui em cheio na figuração do sonho, sob o primado do visual que, como sabemos, não impede um pensamento relativamente complexo. Mas a figuração do sonho, assim como o pensamento por imagens, comporta seus limites.

No melhor dos casos, é a linguagem que vem assumir seu lugar nas zonas de sombra do visível: "Quando você fala, fica mais claro", diz a criança citada por Freud. A ausência, o invisível, colocam o sujeito à prova de suas capacidades de elaboração mental; Freud indica, assim, como, nos sonhos, uma lacuna no material representativo é um meio indireto de representação do sexo feminino.

Mas quando as capacidades de representação imaginária atingem seus limites, uma angústia catastrófica vem à luz, um tipo de afânise, forma arcaica da angústia de castração segundo Jones, face à ameaça de perder sua capacidade de representação. No sonho, estes limites assinalam-se pelo aparecimento do que chamarei os mecanismos do manifesto ${ }^{7}$, para distingui-los dos mecanismos de colocação em latência da censura, executando a articulação representação verbal/ representação visual. Estes mecanismos traduzem o fracasso da função onírica, e mesmo o estado de alerta no interior do sonho, e se encontram freqüentemente nos sujeitos que devem gerir um material irrepresentável importante (estados-limite). A tela do sonho aparece então a nu, como uma tela usada nos interstícios de uma pintura insuficiente. É a irrupção do negativo culminando na alucinação negativa, na perda de consciência, nas condutas automáticas ou nos raptus afetivo-motores.

Em menor grau, estes mecanismos podem, contudo, invadir o sonho e o pensamento vigil. São principalmente: a repetição, quando assume um caráter estereotipado ou obsessivo, ou ainda a impressão de déjà vu ou "sonho no sonho",

6. Cf. meu trabalho "La bouche d'ombre", sobre a angústia de castração e a representação, Revue franç. Psychanalyse, 1998a.

7. Para opô-los aos mecanismos habituais da censura, da ordem da colocação em latência. Cf. Duparc, L'élaboration en psychanalyse, capítulo 3, 1998 b. 


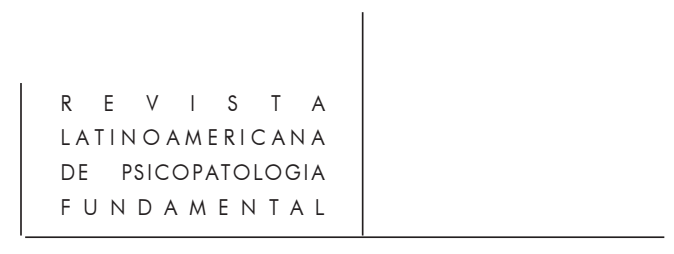

testemunhando um processo de fixação traumática em uma percepção (em vez de uma representação elaborada) para preencher uma brecha na representação, em geral autorizando apenas um fraquíssimo deslocamento simbólico; o retorno no contrário, mecanismo bastante primitivo que constitui uma última muralha contra o afeto, a carga representativa não conseguindo ligar-se a representações suficientemente continentes - às vezes substituídas por uma impressão de paralisia da vontade ou de absurdo, traduzindo um conflito violento com a censura; enfim, o branco, a censura maciça (censura russa ou que usa tarjas de $A$ interpretação dos sonhos), irrompendo no interior do sonho, em geral acompanhado por um afeto intenso levando ao despertar. Bertram Lewin (1946) assinala assim que, em certos pacientes, principalmente os ciclotímicos, um sonho branco acompanhado por uma sensação de orgasmo é às vezes o sinal precursor de uma recaída. Uma de minhas pacientes, também ela com um significativo núcleo autístico, teve um sonho muito impressionante e que tinha, aliás, precedido uma piora em sua sintomatologia: ela sonhara com uma onda, como a paciente citada na introdução, mas esta era feita de areia branca, e a recobria até que tudo desaparecesse nela e em sua volta. Ela acordou em um estado próximo da despersonalização.

A consequiência destes mecanismos é provocar, em geral, no analista, um tipo de sideração do imaginário. O paciente dando a ver em excesso, por seu comportamento repetitivo, um afeto exclusivo, associações por demais abundantes ou uma teatralidade excessiva, em uma atividade mais "adormecedora" do que realmente representativa, satura a capacidade de representação mental no analista. Estes "toxicômanos do manifesto" são por isso pacientes às vezes muito aborrecidos, às vezes muito sedutores, mas sempre difíceis. Tive, por exemplo, um paciente que anotava integralmente todo o conteúdo das sessões, mal estas tinham terminado, assim como seus pensamentos entre cada sessão, com medo de esquecê-los. Claro, isso paralisava toda a análise, e foi necessário um longo trabalho para fazer com que interrompesse esta prática, que visava o controle da irrupção inopinada, em sua consciência, de qualquer imagem acompanhada de afeto. Este aspecto por si só assinalava a gravidade de sua patologia, tanto quanto suas práticas de travestismo e exibicionismo.

Antes de terminar com este nível da representação visual, assinalarei que um dos objetivos essenciais deste nível é conseguir figurar o negativo que não seja pelo branco, pela confusão ou pela fixação perceptiva. A representação do mau, do horrível, do monstruoso, é sempre uma conquista em relação à ausência de representação, principalmente quando uma clivagem clara é estabelecida entre as representações, protegendo o sujeito. ${ }^{8}$ Vamos a um exemplo.

8. Cf. meu artigo "Sujet à confusion" (1991a) sobre o papel da clivagem como separação para o sujeito da confusão primária das representações. 


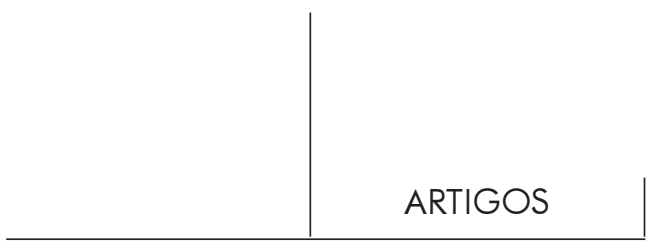

Alexandre é um jovem adolescente encaminhado para uma psicoterapia. Ele esconde, por trás de uma atitude extremamente desdenhosa e cínica, um grave sofrimento depressivo e idéias suicidas inquietantes. Seu discurso muito sofisticado é uma fachada; percebe-se, em um segundo plano, uma grave carência de holding, ligada às diversas mudanças de país e à profissão absorvente de seus pais. No tratamento, rapidamente, o olhar assume uma importância primordial. Ele constituía o único meio, para Alexandre que havia mudado três vezes de língua, de encontrar as emoções de sua infância e comunicá-las para mim. Sem isso, eu tinha a impressão de vê-lo esvaziar-se em uma linguagem racional mortificada, pseudo-adulta. Uma vez quebrado este falso discurso gelado, longas sessões de silêncio se instalaram, ricas em emoção. Com o tempo, meus olhos doíam por ter de sustentar seu olhar. Eu me sentia, no entanto, firme na certeza de que se houvesse relaxado um só momento este modo de contato, Alexandre teria experimentado a impressão de uma queda catastrófica, correndo o risco de levá-lo a uma regressão inquietante, fato que se produziu uma ou duas vezes.

Ao cabo de um certo número de sessões, meus olhos cansados começaram a perceber, no fluido, um tipo de semi-alucinação onírica: em lugar do rosto do rapaz, eu tinha a impressão, por momentos, de ver uma caveira. Seus olhos pareciam-me afundarem-se em suas órbitas, e suas pupilas negras surgiam-me como buracos sem olhar. Eu prestava, então, ainda mais atenção ao que eu compreendi ser um fenômeno de identificação pelo olhar. Intervim para retomar com ele o tema da morte, já evocado pelo paciente, e fiquei sabendo desta vez de dois fatos muito importantes; por um lado, o suicídio de uma irmã de sua mãe pouco antes de seu nascimento, e o temor escondido de seus pais de que ele tivesse uma doença parecida com dela; e, por outro, que ele acreditou por muito tempo que sua ama tivesse morrido, após sua saída.

A partir de então, ele começou a melhorar e a falar mais, de uma forma diferente do começo, já que mais habitado de afetos. Pudemos conversar a respeito deste luto impossível, desta imagem gelada, encriptada nele, servindo-lhe certamente de páraexcitações face às angústias de separação, mas tendo se tornado ao longo do tempo uma tela opaca face aos outros, uma carapaça - Alexandre falava de uma concha de madrepérola no interior de si. O papel do olhar entre nós foi abordado, ele percebeu que pudera, graças a isso, encontrar sua ama em mim, mas uma ama devendo desta vez prepará-lo melhor para uma separação inelutável: ele sabia que devia voltar para seu país, para ir à universidade.

Após ter falado sobre isso um certo tempo, ele mesmo pediu para deitar-se sobre o divã, com o que concordei, não sem hesitação. Mas, após um breve momento de regressão, tudo correu bem, durante o ano que precedeu sua partida. Ele trabalhou por muito tempo a questão da ligação entre o olhar e sua curiosidade sexual, seu ciúme em relação ao casal de pais, que havia favorecido o recurso à imagem 


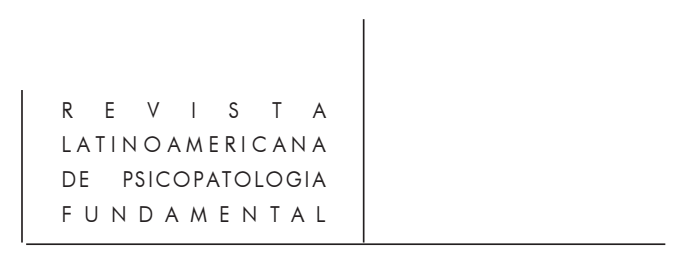

idealizada, fálica, de sua ama, e na transferência. Depois, ele terminou sua análise em uma configuração edípica completamente aceitável.

O mais mutativo neste tratamento foi o momento em que pude sentir com ele, em uma semi-alucinação negativa, a imagem mortificada de sua ama ausente, incorporada nele. O que se tornou visível para mim, ainda era para ele apenas irrepresentável. Era necessário que eu desempenhasse, com ele, esta morte para que sua representação pudesse advir, figurar-se em seu rosto. Esta representação visual, contendo todos os seus afetos, foi em seguida traduzida em uma linguagem comum feita de representações verbais barradas, até então, pelas rupturas lingüísticas. Esta representação pôde enfim ser elucidada e, acima de tudo, clivada em aspectos bons e maus do objeto, esta ama que o havia ao mesmo tempo amado e abandonado, como seus pais.

c) No nível mais arcaico, o da motricidade e do afeto, será que se pode ainda falar de representações? Isso pode ser defendido pelo afeto, sendo, ao mesmo tempo, uma preparação e uma inibição da ação. Isso também pode ser concebido e afirmado a posteriori por certos atos tendo valor simbolizante, pois servem à encenação de vividos que ainda não haviam podido ser representados anteriormente pelo sujeito. Não nos esqueçamos de que o afeto e a motricidade, em certos limites, podem servir de meio de comunicação com o outro, em particular na identificação projetiva. ${ }^{9}$

Se o termo identificação projetiva é com frequiência empregado pelos autores tanto kleinianos quanto não-kleinianos, seu mecanismo exato continua misterioso. Acredito que não se pode realmente compreendê-lo sem recorrer à noção de imitação, incorporação dos afetos do outro por um mecanismo de identificação à sua mímica, aos esboços motores de sua gestualidade. ${ }^{10}$ Este apelo à empatia é sustentado pelo que permanece de instinto materno ou parental no homem, para ser em seguida assimilado e interpretado no interior do imaginário do receptor, sua "capacidade de rêverie materna" (conforme a expressão de Bion). No face a face, momento privilegiado da primeira comunicação no lactente, é o rosto do outro que pode conter e auxiliar a representação dos afetos irrepresentáveis para o próprio sujeito, ajudandoo a figurar-se o bom e o mau, o prazer e a dor, como no caso de Alexandre.

Nesse sentido, o afeto, a emoção, já é um esboço de representação. É isso que me parece poder ser deduzido dessa passagem de uma discussão de Freud em 1907, nas Minutas da Sociedade de Viena: "A pulsão liga o orgânico ao psíquico. Mas a

9. Alguns, como Michel Fain, preferem o termo identificação histérica primária ao termo kleiniano de identificação projetiva.

10. Este fenômeno era conhecido de Freud, ela fala sobre isso a propósito da capacidade de adivinhação dos videntes, graças aos pequenos movimentos involuntários do sujeito durante a representação. Cf. "Traitement psychique", 1890, p. 7. 


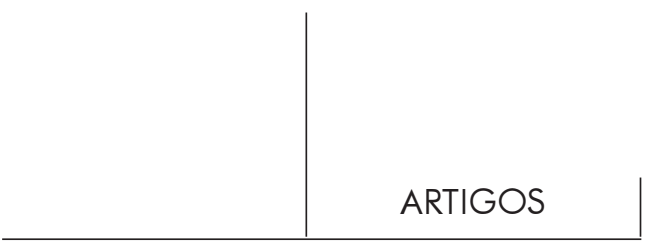

emoção pertence completamente ao psíquico [...]. As percepções suscitam emoções (= afetos); estas emoções são ações internas". (p. 155)

Penso que é à representação visual que pertence o papel de conter, organizar e triar o conteúdo confuso próprio ao nível primário destas representações-afetos, ou representações motoras, sendo elas mesmas representações brancas, sem conteúdo visual. ${ }^{11}$

A idéia de estratificar a representação em três níveis parece-me coerente com a metapsicologia freudiana. Apesar de algumas anotações em "O inconsciente" e em "O recalcamento", o único texto em que Freud (1926) se põe a definir realmente a representação é seu trabalho pré-psicanalítico sobre as afasias. Nele já encontramos sua concepção das representações de palavra e das representações de coisas, quase sem diferenças com sua utilização posterior. Mas ele precisa aqui que é a representação visual que está encarregada da ligação entre os traços motores, cenestésicos e outros, que constituem a representação de coisa, por um lado, e a representação de palavra, por outro. Ele indica, além disso, que a representação de palavra é "fechada" em relação à representação de coisa. Tem-se verdadeiramente a impressão de que a representação de nível superior "contém”, limita, encerra e organiza aquela que lhe é subjacente, simbolizando-a. Esta perspectiva permite, aliás, melhor compreender a regressão do sonho a um pensamento visual, intermediário entre a representação de palavra e a parte da representação de coisa mais próxima da motricidade e do afeto. ${ }^{12}$

Quando o face a face é utilizado com certos pacientes, isso é feito em virtude da confiança que se tem na capacidade organizadora da representação visual em relação às tendências do agir, da somatização ou do afeto despersonalizante, catastrófico, correndo o risco de irromper em uma situação analítica clássica. Existem, portanto, núcleos de irrepresentável que não podem ser tratados pela fala. A fala não tem, nesse caso, função de representação nem de continência para estes núcleos traumáticos tendendo à descarga. Ela pode até constituir um objeto inassimilável e traumático, seja porque o paciente se "esvazia" de sua linguagem sem poder dela conservar o menor traço, e sentindo nesta ocasião um prazer letal, seja porque ele tem a impressão de uma hemorragia em benefício de um analista-vampiro, que não lhe remete nenhuma representação de si mesmo em espelho. $\mathrm{O}$ face a face, pelo contrário, fornece um enquadre, com um ponto de ancoragem no olhar do outro, e

11. Aquelas que encontramos na alucinação negativa: tela branca, agitação motora, afetos despersonalizantes, agradáveis ou desagradáveis, mas sem conteúdos imaginários. Cf. meu artigo sobre a alucinação negativa (1996).

12. Representação que M. Perron-Borelli (1987) justamente propôs chamar "representação de ação", para insistir sobre o fato de que se tratava mais do traço de uma relação com um objeto investido do que de um objeto inerte. 


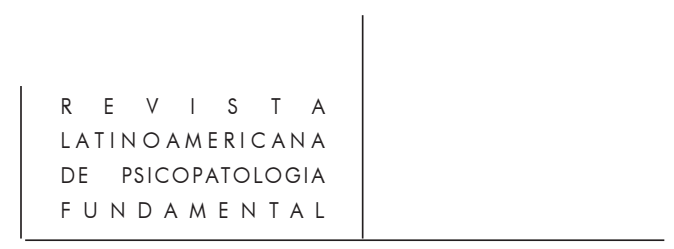

uma cena, o espaço do olhar, podendo se estabelecer e se clivar as representações mímicas imitativas do prazer, da dor etc. O psicodrama, o jogo teatral, podem aí acontecer como complemento para organizar o sentido, acrescentando uma ação limitada pelas regras de uma convenção na expressão do afeto.

Aqui, a representação visual existe, porém mais no analista, no intérprete ou no diretor, do que no sujeito nela engajado com seus afetos e com todo o seu corpo. Este, sob o domínio de comportamentos automáticos de que não tem consciência, quase não tem a possibilidade de controle. Como o sujeito, preso a este tipo de irrepresentável, pode se limitar para evitar entregar-se a uma descarga alucinatória sem freio e mortífera? Acrescentamos, aqui, a questão de minha paciente enfermeira. Para compreendê-lo, é preciso apelar aos comportamentos dos autistas, tão bem descritos por Frances Tustin (1986). Certas sensações provocadas por estimulações repetitivas, movimentos (as "formas" autísticas) ou objetos apropriados são empregadas como limites muito primitivos, alucinações negativas de qualquer objeto externo, correndo o risco de ser perdido. Estes objetos ou formas autísticas formam carapaças, moles ou duras, rígidas ou confusas, sensuais ou dolorosas, para afastar o risco mortal de queda, de descarga e de despejo representativo.

Tive, assim, em terapia, uma paciente gravemente anoréxica, que nunca se separava dos pequenos objetos metálicos que manipulava constantemente em seu bolso; ela confessava que isso a ajudava a isolar-se completamente do mundo externo. Quando estava muito faminta, servia-se de um animal de pano, cheio de areia: o rangido da areia no interior permitia-lhe esquecer suas próprias sensações corporais, principalmente a excitação, sendo vivida como aterradora. Tinha, então, a impressão de ser a areia, contida no interior da bolsa forrada. Ela também podia absorver-se inteiramente na contemplação de um buraco na parede, em frente à sua janela. Isso lhe permitia parar de pensar e ficar vazia. Nas sessões, não prestava atenção alguma em mim; o som de minha voz parecia-lhe um banho agradável. Mas a partir do momento em que minha presença ultrapassava este simples papel de envelope e, sobretudo, a partir do momento em que uma ameaça de separação se perfilava, eu simplesmente não mais existia para ela. Ela não podia expressar a menor agressividade: apenas uma enorme indiferença aparecia em relação a mim, e um recurso crescente às suas técnicas de auto-erotismo vazio.

\section{O trabalho nos limites}

O irrepresentável é geralmente, como disse na introdução, depositado em um objeto fetiche, herdeiro de um objeto autístico mais ou menos manifesto da infância (em vez do objeto transicional de Winnicott), ou ainda em um enquadre auto-erótico rígido, isolando o paciente do mundo externo como uma carapaça, uma couraça caracterial. Conforme o nível da representação que, dessa forma, faltou, o trabalho 


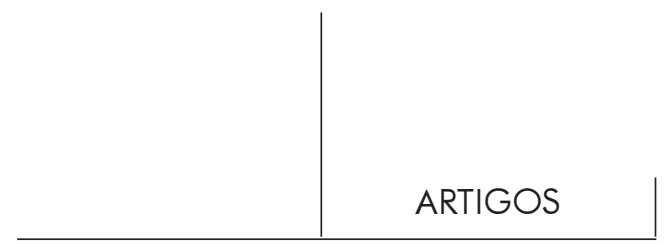

nos limites é, certamente, diferente. As indicações técnicas dependem da avaliação que poderá ter sido feita disso.

a) No nível verbal, a única técnica requerida é a da interpretação. Os núcleos de fixação são imaginários, em geral organizados por um fantasma originário por demais prevalente, bloqueando a circulação e a elaboração fantasmática. ${ }^{13}$ A interpretação pode variar consideravelmente de um sujeito a outro, conforme a avaliação da zona em que se situa a repetição. Um caráter neurótico nem sempre é tão fácil de ser reduzido: será que o irrepresentável, por ser moderado em sua estrutura, estaria, nesses casos, particularmente estendido?

Na histeria, um núcleo traumático ligado à cena primitiva está sempre presente e é objeto de uma intensa dramatização corporal ou motora, desempenhada por um espectador. A interpretação deve procurar conter e clivar a carga afetiva da cena traumática, a fim de elaborá-la. Assim contido, auxiliado por construções ou retomadas repetitivas para reduzir a dramatização, o sujeito pode tentar um deslocamento em direção ao fantasma de retorno intra-uterino, por exemplo, ou em direção à angústia de castração. Na neurose obsessiva, é, pelo contrário, o isolamento destrutivo e a racionalização repetitiva que é preciso reduzir, e uma certa dramatização é freqüentemente necessária para sair de uma tendência à mortificação e à incorporação sádica dos objetos amados (conforme o fantasma originário de assassinato do pai ou do rival). Na neurose fóbica, a prevalência do fantasma de sedução impõe uma contenção da angústia por interpretações esforçando-se para identificar o objeto fóbico, a fim de neutralizar-lhe a erotização perigosa etc.

b) No nível visual, tudo depende se nos encontramos em presença de uma fixação a uma imagem fetiche, da ordem da percepção alucinatória, contra-investindo uma falta de representação mental mais elaborada, ou então se nos encontramos em face de uma verdadeira carência imaginária, que deixa pressentir recursos a comportamentos motores ou carapaças auto-eróticas sem representação que não sejam muito primitivas. No primeiro caso, o único de que nos ocupamos aqui, o analista deve resolver ser o depositário de imagens extremamente idealizadas, com frequiência em um face a face que só ele permite a transferência destas imagens, por meio do apoio sobre o olhar e sobre a cena do rosto. O que é transferido, como vimos no caso de Alexandre, são as zonas de sombra da imagem ideal ${ }^{14}$ insuportáveis para o sujeito, irrepresentadas pois ameaçam qualquer representação possível do objeto amado. A ausência do objeto não pode se projetar senão sobre uma presença estável, a única permitindo o luto. Às vezes, é a imagem sonora que é investida, e o sujeito

13. Cf. meu artigo sobre os fantasmas originários (1991), ou meu livro L'élaboration en psychanalyse (1998b).

14. Cf., por exemplo, o trabalho de César e Sarah Botella (1990) sobre a alucinação. 


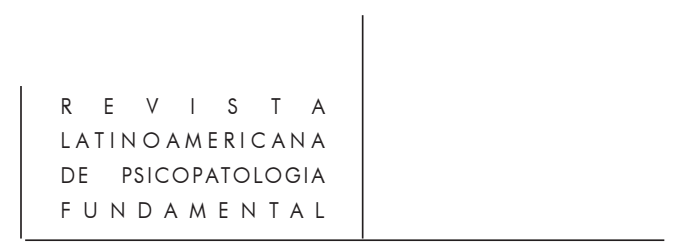

pode desejar ficar deitado sobre o divã, mas não suportará um silêncio por demais prolongado por parte do analista. $\mathrm{O}$ banho de sons desempenha o papel de um espelho, como o rosto no face a face.

c) No nível dos traços afetivo-motores sem representações mentais associadas, encontramo-nos nos confins da psicose e da psicossomática, em um domínio em que as técnicas mais se afastam do tratamento clássico. Uma técnica que às vezes emprego nesses casos difíceis é a associação de um relaxamento sobre o divã e um face a face, com interpretações sobre a "linguagem" corporal. ${ }^{15}$ Utilizei-a, assim, com um paciente alcoolista que sofre de uma afecção psicossomática grave, com risco de vida.

É também a única forma que encontrei de conter e suportar a paciente anoréxica de que falava há pouco; o único meio que lhe permitiu estabilizar-se relativamente em seus comportamentos autodestrutivos, conseguindo evitar-lhe a repetição de hospitalizações emergenciais. Ela se deitava sobre o divã; eu me instalava ao seu lado e a observava atentamente. Com freqüência, ela fechava os olhos, e só os abria de tempos em tempos, para se assegurar de minha expressão enquanto eu falava. Comecei, então, a descrever-lhe o que ela sentia, de uma forma descontínua, em uma espécie de comentário de seus atos, muito comparáveis ao que os sujeitos sentem de forma persecutória no automatismo mental. Quando eu me enganava, ela me fuzilava com os olhos e me censurava com energia. Foi por eu imitar suas atitudes, caricaturando-as fortemente, em um tipo de psicodrama a dois, que ela conseguiu progredir para uma melhor representação de seus afetos, totalmente negada no início; por exemplo, eu lhe representava com força a forma como ela me odiava ao chegar à sessão, tinha vontade de me vomitar como seu alimento tão detestado, quando ela não conseguia me encontrar, principalmente após uma ausência. Em contrapartida, quando parecia relaxada, eu lhe descrevia o desejo que ela tinha de se alimentar de minhas palavras e de adormecer molemente sobre o divã. Pouco a pouco, pude abandonar esta transfusão fantasmática para escutá-la retomar todas as minhas interpretações anteriores, associando-as a cenas de sua história as quais me contava de uma forma muito teatral: déramos um passo apreciável rumo à histeria, e ela abandonou sua anorexia tão inquietante por uma bulimia transitória.

Com esta última técnica, se não fosse o recurso à identificação projetiva, ou ainda a utilização de interpretações da ordem da clivagem, eu teria podido ter a

15. Por linguagem corporal, compreendo esboços de "representações motoras": atitudes emotivas, gestualidade que chamam a identificação empática do analista (ver acima, a propósito da identificação projetiva). Quanto à técnica empregada, que pode parecer uma aberração na perspectiva de uma análise ou mesmo de uma psicoterapia analítica "clássica", ela constitui, no entanto, um enquadre específico, a psicoterapia de relaxamento de inspiração psicanalítica. 


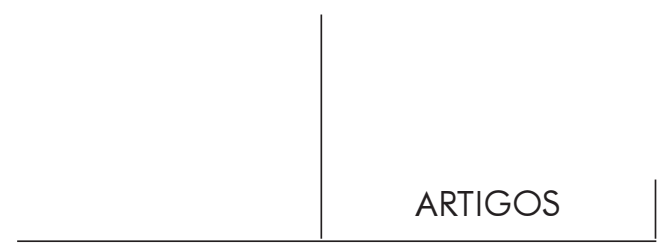

impressão de me encontrar utilizando a técnica ativa de Ferenczi! (1978). Mas a vantagem de uma maior elaboração metapsicológica da noção de representação é que, como regra, estas medidas não representaram para meus pacientes senão uma etapa inicial do tratamento, a seqüência da evolução permitindo sempre progredir em direção a um tratamento muito mais clássico.

Mas será que respondi à questão colocada pela paciente de minha introdução? Onde se situam os limites, nesses casos extremos?

O limite, tentei mostrá-lo, é constituído pelo que resta da ordem do irrepresentável, devendo ajudar a contê-lo: este irrepresentável não deve tornar-se suportável senão à condição de ser triado, elaborado em representações de nível superior, mais estáveis, comportando zonas positivas e negativas, em pares contrastados: prazer/dor, presença/ausência, apoio ou queda no vazio, fala e silêncio. Estas oposições, além disso, devem obedecer a um certo ritmo, próprio a cada sujeito. Retomadas no nível do imaginário, depois no das representações verbais, estas figuras darão, enfim, origem à lei moral, última etapa, regulando, pelas estruturas do superego e do ideal, o acesso limitado ao prazer, que a realidade impõe.

Referências

Bleger, J. (1966). Psychanalyse du cadre psychanalytique. In Symbiose et ambiguité. Paris: PUF, 1981.

Botella, C. e S. La problématique de la régression de la pensée et de l'hallucinatoire. In La psychanalyse pour demain, Monographies de la Revue Française de Psychanalyse. Paris: PUF, 1990.

Dejours, C. Recherches psychanalytiques sur le corps. Paris: Payot, 1989.

DupARC, F. Respiration de la parole et mouvements du sens. Revue Française de Psychanal., 1988, t. 52, no 2.

Transfert latéral, transfert du négatif. Revue Française de Psychanal. 1989, t. 52, no 4 .

Les objets infinis du mélancolique. Revue Française de Psychanalyse. 1989a, t. 53, no 1 .

Vie et mort des représentations. Revue Française de Psychanal., 1989b, t. 53, no 6.

Qu'avez-vous donc tiré au jeu des fantasmes originaires? Revue Française de Psychanalyse. 1991, t. 55, no 5 .

Sujet à confusion. Revue Française de Psychanalyse. 1991a, t. 55, ํㅜ 6.

La bouche d'ombre, angoisse de castration et position dépressive dans les deux sexes. Exposto no Colóquio franco-italiano. Roma, dezembro de 1991; Psychanalyse à l'Université. Paris: PUF, 1992, nº 68.

L'image sur le divan. Paris: L'Harmattan, 1995, 315 p.

Hallucination négative, formes motrices et comportements autocalmants. In 
Cliniques psychosomatiques, Monographies de la Revue Française de Psychanalyse. Paris: PUF, 1996.

La cyclothymie, de la névrose à la psychose maniaco-dépressive. In Psychose, t.

1, Monographies de la Revue Française de Psychanalyse. Paris: PUF, 1998.

L'opératoire, entre clivage et forclusion. Revue Française de Psychanalyse. №s 56, 1998a.

L'élaboration en psychanalyse. Préface d'A. Green. Bordeaux, L'Esprit du Temps, difusão PUF; 1998b, Paris, 300 p.

Fain, M. e David, C. (1962). Aspects fonctionnels de la vie onirique. Revue Française de Psychanalyse. t. 27, 1963.

Ferenczi, S. (1912). Le développement du sens de la réalité et ses stades. In Oeuvres. Paris: Payot, 1978. t. 2.

(1924). Les fantasmes provoqués. In Oeuvres. Paris: Payot, 1974. t. 3.

(1926). Le problème de l'affirmation du déplaisir. In Oeuvres. Paris: Payot, 1974. t. 3 .

Freud, S. (1890). Traitement psychique (traitement d'âme). In Résultats, idées, problèmes I. Paris: PUF, 1984.

(1891). Contribution à la conception des aphasies. Paris: Gallimard, 1983.

(1900). L'interprétation des rêves. Paris: PUF, 1973.

(1906-1908). Les premiers psychanalystes. Minutes de la Société psychanalytique de Vienne. Paris: Gallimard, 1976. t. I. (1915). L'inconscient. In Métapsychologie. Paris: Gallimard, 1968.

GREEN, A. (1982). La double limite. In La folie privée. Paris: Gallimard, 1990.

Lewin, B. (1946). Sleep, the Mouth and the Dream Screen. Trad. franc in Nouvelle Revue de Psychanalyse, 1972, no 5 .

(1950). The Psychoanalysis of the Elation. Psychoanalytic Quarterly Press, 1961.

McDougall, J. Le rêve et le psychosoma. In La psychanalyse, questions pour demain, Monographies de la Revue Française de Psychanalyse. Paris: PUF, 1990.

Perron-Borelli, M. e Perron, R. Fantasme et action. Trabalho apresentado no Congresso de Liège, 1986. Revue Française de Psychanalyse, 1987, t. 51, no 2.

Pragier, G. e Faure-Pragier, S. Psychanalyse et sciences: nouvelles métaphores. Revue Française de Psychanalyse, 1990, t. 54, no 6.

Tustin, F. (1986). Le trou noir de la psyché. Paris: Seuil, 1989.

Winnicotr, D.W. (1963). De la régression considérée comme une thérapie. In De la pédiatrie à la psychanalyse. Paris: Payot, 1969.

\section{Resumos}

Cuáles son los límites de la interpretación más allá de los cuáles el sujeto se ve confrontado com lo irrepresentable?

Las representaciones comportan diferentes niveles de madurez; consecuentemente 


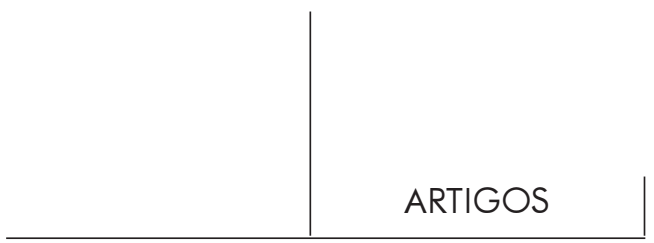

lo irrepresentable comporta grados, es relativo. Esto explica la esperanza que se conserva en el tratamiento de los casos limítrofes, de ciertas formas de psicosis, de perversiones y de disturbios psicosomáticos.

Cada nivel de representación conlleva su tipo de límite, su borde, su negativo, gracias al cual puede entrar en contacto y ligarse tanto con el nivel que lo precede como con el que le sigue y contiene. Se trata de un modelo del orden de la autorización, com niveles de complejidad crecientes.

El límite puede ser tanto interno, constituíndo asi, un límite psiquizado, integrado en el protector contra estímulos, como externo, apelando a un encuadre, a un apoyo externo que deja asi al sujeto extremamente dependiente para su equilibrio narcisista $y$ vital.

Los pacientes “límite” son justamente sujetos dependientes de un encuadre autoerórico externo (encuadre éste com frecuencia faltante) por consiguiente muy flexible, poco adaptado a lo aleatorio de la realidad, como lo sugiere la imagen de un caparazón. Sus pulsiones, mal controladas por representaciones primarias en las que la figuración perceptiva domina la ligadura verbal, tienen tendencia a descargarse brutalmente a partir del momento en que el objeto externo, o lo que lo sustituye, falta en su función de apoyo.

El "trabajo en los límites" del analista es hecho evaluando la parte irrepresentable de la que el paciente sufre y por una téctica adaptada que auxilia la representación, adaptada a su vez a cada estructura y a cada historia. Esto será ilustrado com casos clínicos.

Palabras claves: Representaciones, límites, negativo, encuadre, apoyo

Quelles sont les limites de la représentation, au-delà desquelles le sujet se voit confronté à l'irreprésentable?

Les représentations comportent différents niveaux de maturité; par conséquent l'irreprésentable comporte des degrés, il est relatif. Ceci explique l'espoir que l'on conserve dans la cure des états-limites, ou dans certaines formes de psychoses, de perversions ou de troubles psychosomatiques.

Chaque niveau de représentation comporte son type de limite, sa bordure, son négatif, grâce auquel il peut entrer en contact et se lier, aussi bien avec le niveau qui le précède, qu'avec celui qui lui succède, et le contient. II s'agit d'un modèle de l'ordre de l'auto-organisation, avec des niveaux de complexité croissante.

La limite peut être soit interne, constituant alors une limite élaborée, psychisée, intégrée dans le pare-excitations; soit externe, faisant appel à un cadre, à un étayage externe dont le sujet est alors extrêmement dépendant pour son équilibre narcissique, voire même vital.

Les patients "limites" sont précisément des sujet dépendants d'un cadre autoérotique externe, cadre souvent défaillant car très peu souple, peu adapté aux aléas de la réalité, comme le suggère l'image de la carapace. Leurs pulsions, mal contrôlées par 
des représentations primaires, où la figuration perceptive domine sur la liaison verbale, ont tendance à se décharger brutalement dès que l'objet extérieur, ou ce qui en tient lieu, fait défaut à sa fonction d'étayage.

Le "travail aux limites" de l'analyste est fait d'une évaluation de la part d'irreprésentable dont souffre le patient, et d'une technique adaptée d'aide à la représentation, adaptée à chaque structure, et à chaque histoire. Des exemples cliniques l'illustreront.

Mots clés: Représentations, limites, négatif, cadre, étayage

Where are the boundary lines of representation beyond which the subject is faced with the unrepresentable?

Representations allow for different levels, or degrees, of maturity. They are relative. This gives one reason for favorable prognoses in the treatment of patients with borderline states or certain forms of psychoses, perversions or psychosomatic disturbances.

Each level of representation has its own type of boundary line, its enclosure, its negative, by which it can come into contact with the level that precedes it, as well as with that which follows and contains it. It is a model like that of self-organization, with increasing levels of complexity.

Boundary lines can be either internal or external. Internal boundaries are worked through and integrated in para-excitation, whereas external boundaries refer to a setting, an external support on which the subject then becomes extremely dependent for its vital, albeit narcissistic, equilibrium.

"Boundary" patients are subjects that depend on an external self-erotic setting, a setting that is often lacking because it is exceedingly flexible and not well adapted to the randomness of reality, as the image of armor might suggest. These patients' drives, poorly controlled by primary representations where perception dominates verbal connections, tend toward strong discharge when the outside object, or whatever replaces it, fails in its support function.

The analyst "works on the boundary lines" by appraising the unrepresentable part the patient is suffering from, using techniques adapted as aids to representation, in accord with each structure and each history. This is illustrated with clinical cases.

Key words: Representations, boundaries, negative, setting, support

Versão inicial recebida em janeiro de 2001

Versão revisada recebida em novembro de 2001 